\title{
Organic farming enhances parasitoid diversity at the local and landscape scales
}

\author{
Diego J. Inclán ${ }^{1,2 *}$, Pierfilippo Cerretti ${ }^{1,3}$, Doreen Gabriel ${ }^{4}$, Tim G. Benton ${ }^{5}$, Steven M. \\ Sait $^{5}$, William E. Kunin ${ }^{5}$, Mark A. K. Gillespie ${ }^{5}$ and Lorenzo Marini ${ }^{1}$ \\ ${ }^{1}$ DAFNAE-Entomology, University of Padova, Viale dell'Università 16, Legnaro, Padova 35020, Italy; \\ ${ }^{2}$ Research Associate, Museo Ecuatoriano de Ciencias Naturales, Sección Invertebrados, Rumipamba 341 y Av. de \\ los Shyris, Quito, Ecuador; ${ }^{3}$ Department of Biology and Biotechnology 'Charles Darwin', Sapienza University of Rome, \\ Piazzale A. Moro 5, Rome 00185, Italy; ${ }^{4}$ Institute of Crop and Soil Science, Julius Kühn-Institut (JKI), Federal \\ Research Centre for Cultivated Plants, Bundesallee 50, Braunschweig D-38116, Germany; and ${ }^{5}$ School of Biology, \\ Faculty of Biological Sciences, University of Leeds, Leeds LS2 9JT, UK
}

\begin{abstract}
Summary
1. The magnitude of the benefits derived from organic farming within contrasting managed landscapes remains unclear and, in particular, the potential scale-dependent response of insect parasitoids is relatively unexplored. Identifying the scale at which parasitoids are affected by organic farming will be an important step to enhance their conservation.

2. We sampled tachinid parasitoids at the centre and margin of arable and grassland fields on paired organic and conventional farms located in landscapes with different proportions of organic land. A total of 192 fields were sampled in two biogeographical regions of the UK.

3. We found that the positive effect of organic farming on tachinid parasitoid diversity can be observed at multiple spatial scales. At the local scale, we found higher abundance and species richness of tachinid parasitoids on organic than on conventional farms and on field margins than on field centres. At the landscape scale, the diversity of tachinids was higher in landscapes with higher proportions of organic land. At both scales, the positive effect of organic farming was clear for arable fields, while it was almost neutral for grasslands.

4. Synthesis and applications. Any attempt to enhance parasitoid diversity in agricultural landscapes needs to consider the local management in relation to the habitat type, location within the field and agricultural management in the surrounding landscape. To restore parasitoid diversity, the promotion of organic agriculture should aim to increase both the total extent of organic farming and the connectivity of individual farms. As the benefits of organic farming to biodiversity clearly spread beyond individual farm boundaries, any assessment of organic farming should consider these positive externalities.
\end{abstract}

Key-words: agricultural intensification, agri-environment schemes, biocontrol, conventional farming, management, natural enemies, scale dependence, Tachinidae

\section{Introduction}

In the last few decades, agricultural intensification has strongly increased crop productivity through mechanization and the use of improved crop varieties, chemical fertilizers and pesticides leading to severe ecological simplification of European agroecosystems (Swift et al. 1996; Tilman et al. 2001; Wilby \& Thomas 2002; Bengtsson, Ahnström \& Weibull 2005; Fuller et al. 2005; Geiger et al. 2010; Holzschuh, Steffan-Dewenter \& Tscharntke

*Correspondence author. E-mail: diego.inclanluna@unipd.it
2010). This simplification has resulted in a marked reduction in the diversity of insect natural enemies with possible negative effects on pest control services (Wilby \& Thomas 2002; Bianchi, Booij \& Tscharntke 2006; Macfadyen et al. 2009; Thies et al. 2011; Jonsson et al. 2012). Although it is relatively well known that intensive agricultural systems are responsible for the decline of species diversity and the abundance of natural enemies in general (e.g. Fuller et al. 2005; Letourneau \& Bothwell 2008; Macfadyen et al. 2009, 2011; Lohaus, Vidal \& Thies 2013), the understanding of the effects of agricultural management at different spatial scales on important natural enemies such as parasitoids is still incomplete. 
In Europe, to counteract the decline in farmland biodiversity, several agri-environment schemes (AES) have been implemented, including subsidies to support organic farming. In contrast to conventional agriculture, organic farming is a production system considered to be more sustainable because the use of synthetic fertilizers and pesticides is excluded. These practices increase farmland heterogeneity and often enhance parasitoid diversity and possibly natural pest control (Bengtsson, Ahnström \& Weibull 2005; Letourneau \& Bothwell 2008; Macfadyen et al. 2009, 2011; Crowder et al. 2010), although the specific contribution of insect parasitoid diversity to pest control remains unclear (Finke \& Denno 2004; PérezLachaud, Batchelor \& Hardy 2004; Batchelor et al. 2005). Research on parasitoids has only focused on organic management at the local scale, ignoring potential effects at the landscape scale. Although several studies have considered the effects of landscape composition on insect diversity, this research has mainly focused on the role of seminatural habitats or habitat heterogeneity in the landscape (see review of Tuck et al. 2014), rather than the effects of management type within the same land-use class (but see Holzschuh, Steffan-Dewenter \& Tscharntke 2008; Rundlöf, Edlund \& Smith 2010; Gabriel et al. 2010). The magnitude of the benefits derived from organic farming within diverse agricultural managed landscapes remains unclear. Similarly, while recent research has highlighted that different taxa respond to organic management at different spatial scales (Gabriel et al. 2006, 2010; Clough et al. 2007), the potential scale-dependent response of insect parasitoids is relatively unexplored. Identifying the scale at which parasitoids are most strongly affected by organic farming will be an important step to maximize the benefits from AES and potentially to enhance the biocontrol of pests.

Most of the studies that have elucidated the effect of agricultural management and landscape on parasitoids have focused on single or a few species of hymenopteran parasitoids (e.g. Thies et al. 2011; Jonsson et al. 2012; Lohaus, Vidal \& Thies 2013). In this work, we used tachinids (Diptera: Tachinidae) as an alternative and non-hymenopteran parasitoid group. With almost 8500 species, the Tachinidae family ranks second in diversity within the Diptera and is the most diverse group of nonhymenopteran parasitoids (Stireman, O'Hara \& Wood 2006; O’Hara 2013). Tachinids tend to have a wider range of hosts than hymenopteran parasitoids and can be very important natural enemies of agricultural pests. Tachinids often play significant roles in regulating herbivore populations due to their predominance in attacking the larval stage of lepidopterans, coleopterans, hemipterans and other major groups of insect herbivores (Stireman, O'Hara \& Wood 2006; Cerretti et al. 2014). In general, about 100 species have been employed in biological control programmes of crop and forest pests (Grenier 1988; Stireman, O'Hara \& Wood 2006). Additionally, adult tachinids are flower-visiting insects as they use nectar as an energy source and may even act as pollinators (Al-Dobai, Reitz \& Sivinski 2012), although their importance in this respect has been largely unexplored (Stireman, O'Hara \& Wood 2006). Considering the diversity and crucial role of tachinids as parasitoids, more research is needed to elucidate the effects of management across different scales on this key functional group.

The main aim of our study was to examine how local farm management (organic vs. conventional) and the proportion of land under organic farming in the landscape affects species richness and the abundance of tachinid parasitoids. Specifically, we addressed four main questions. First, due to the marked differences in local management between organic and conventional farming, does organic farming enhance the local diversity of parasitoids? Secondly, if organic management has a positive effect on tachinid diversity, is this effect stronger for arable crops than for grasslands? Thirdly, due to the greater difference in the local management of field centres between the two farming regimes, is there a more pronounced effect of organic farming in field centres than in field margins? Fourthly, according to the source-sink hypothesis (Pulliam 1988), is organic farming acting as a 'source' of parasitoids from where conventional farms could benefit as 'sink' habitats through the spillover of individuals? If so, it is expected that parasitoid diversity in conventional farms located in landscapes with high coverage of organic farming will be greater than in landscapes dominated by conventional agriculture.

\section{Materials and methods}

\section{STUDY AREA AND SAMPLING DESIGN}

The study design and the site selection are described in full detail in Gabriel et al. (2010). In summary, 16 landscapes of $10 \times 10 \mathrm{~km}$ were selected containing different proportions of land under organic farming (Fig. 1a). Landscapes were arranged in eight clusters of paired landscapes. Paired landscapes were chosen to have similar environmental conditions (i.e. very similar landscape composition), but contrasting amounts of organic farming, that is organic 'hotspot' vs. 'coldspot' depending on the proportion of land under organic farming (hotspot mean $17.2 \%$, range $8.936 .8 \%$ vs. coldspot mean $1.4 \%$, range $0.53 .3 \%$ ) (see Gabriel et al. 2009). The paired landscapes within each cluster were located within an average distance of $28 \cdot 3 \pm 14.4 \mathrm{~km}$. Four clusters were located in the Central South West and four in the North Midlands of England (Fig. 1a). Each landscape (both hotspot and coldspot) contained one focal organic and one conventional farm with similar enterprise structure (Fig. 1b). The paired farms were located within an average distance of $2.9 \pm 1.4 \mathrm{~km}$. This study design ensured that the local farm management and the proportion of land under organic farming in the landscape were uncorrelated enabling us to test the interaction between the two scales. Within each farm, three cereal fields (mainly winter wheat) and three grassland fields (mainly grazed permanent pastures) were selected (Fig. 1b). A total of 192 fields were sampled, within 16 organic and 16 conventional farms located in eight clusters divided into two regions. 


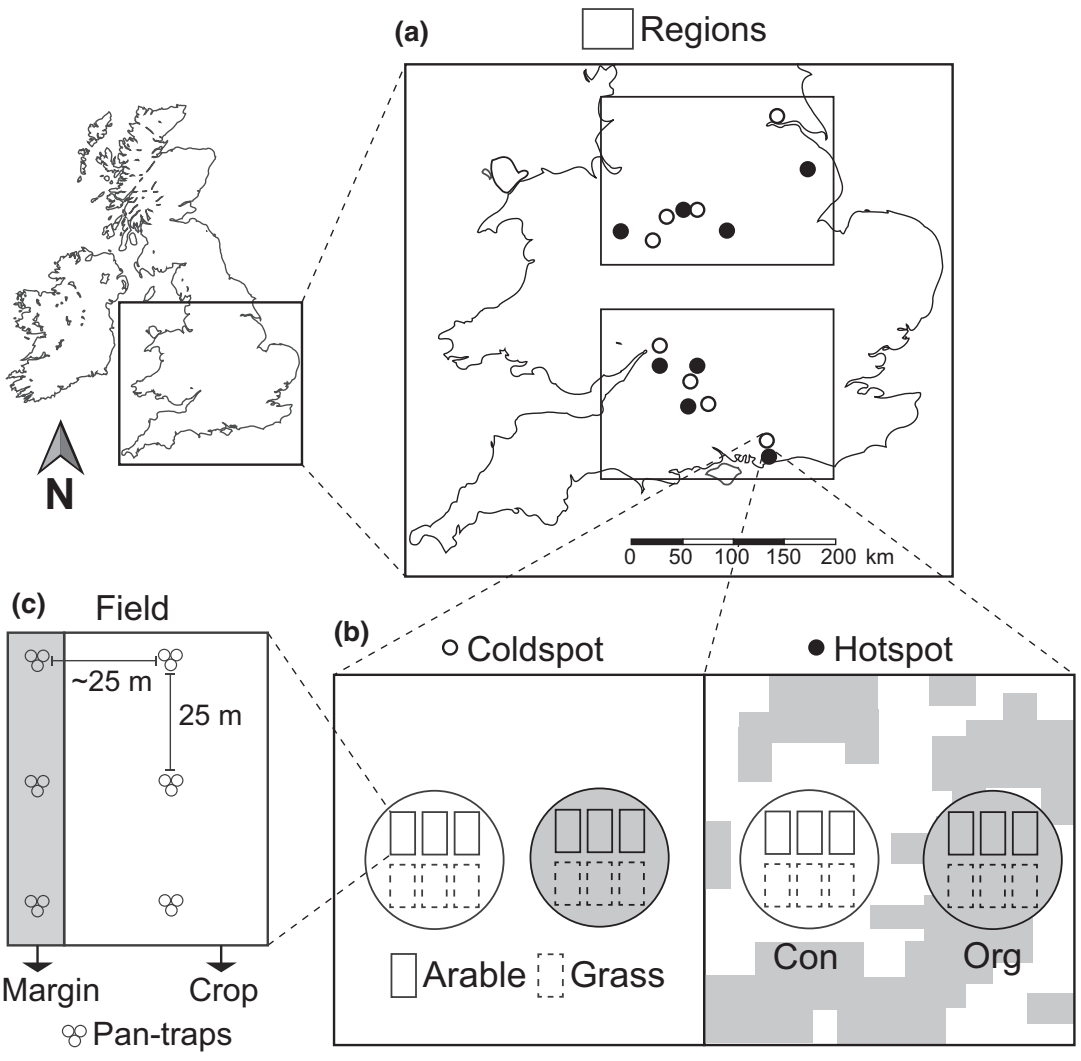

Fig. 1. Scheme showing the hierarchical sampling design. (a) Distribution of the 16 paired landscapes across two regions in England. (b) Landscapes with grey shading representing a low (coldspot) or high (hotspot) amount of organic land in the landscapes. Each landscape contains one conventional (white circle) and one organic farm (grey circle). Farms contain three arable (solid rectangles) and three grass (dashed rectangles) fields. (c) Within each field, three groups of three pan-traps were placed in the field margin and in the field centre.

\section{INSECT SAMPLING}

Within each field, pan-trap sampling was conducted along two transects. The first transect was placed in the margin of the field (uncultivated area), and the second transect was placed in the field centre, about $25 \mathrm{~m}$ from the margin. On each transect, three groups of three pan-traps were placed separated by $25 \mathrm{~m}$ (Fig. 1c). Each group of pan-traps consisted of three UV-reflecting coloured plastic bowls (yellow, white and blue) with an internal diameter of $11 \mathrm{~cm}$. Pan-traps were held just above the top of the vegetation by a wooden stake, and the bowls were half-filled with water to which a drop of detergent was added to break the surface tension. The sampling was conducted twice in 2007 in June and July when the average temperature was above $15^{\circ} \mathrm{C}$. During each sampling round, traps were set for a period of $48 \mathrm{~h}$ after which insects were retrieved and stored in alcohol $(70 \%)$ for sorting and identification. A total of 2304 samples were processed, and the specimens belonging to the family Tachinidae (Diptera) were identified to species level using Cerretti (2010) and Cerretti et al. (2012). All the specimens were housed in the insect collection of P. Cerretti at the MZUR (Museo di Zoologia, Università di Roma La Sapienza, Rome, Italy).

\section{STATISTICAL ANALYSES}

To test the effects of cover of organic land in the landscape (hotspot and coldspot), farm management (organic and conventional), habitat (arable and grassland fields) and trap location (margin vs. centre), we used generalized linear mixed effect models. The response variable was the species richness per field and the total number of individuals per field. For abundance, we used a generalized linear mixed model with a negative binomial distribution. For species richness, we used a generalized linear mixed model with a Poisson distribution. The families and link functions used in the models were selected based on residual deviance and distribution of residuals. Both models included region (Central South West and North Midlands), landscape (hotspot and coldspot), farm management (organic and conventional), habitat (arable and grassland fields) and location (margin and centre) as categorical fixed effects. Both models included landscape cluster $(n=8)$, landscape ID $(n=16)$, farm ID $(n=32)$ and field ID $(n=192)$ as random factors to account for the nested design of the sampling. Although due to its nature region could be a random effect, we include it as a fixed factor because it only had two levels (Bolker et al. 2008). The analyses were performed using the package 'GLMmADMB' (Fournier et al. 2012), implemented in R 3.0.2 (R Development Core Team 2013).

To compare the fit of all the possible combinations of predictors in our models, we used the second-order Akaike's information criterion (AICc) corrected for small samples (Whittingham et al. 2006). We first built a global model containing the variable region and all the interactions among landscape, farm management, habitat and location. Region was not included in any interactions, as we did not have any ecological hypothesis to support these analyses. We compared all the models using $\triangle \mathrm{AICc}$ and Akaike weights $\left(\sum w_{\mathrm{i}}\right)$. A model is usually considered plausible if its $\triangle$ AICc is below two (Burnham \& Anderson 2002). To evaluate the relative importance of each predictor, we summed the $w_{\mathrm{i}}$ across the models in the set in which the predictor occurred. The model inference analyses were performed using the 'MuMIN' package (Barton 2013) implemented in R ( $\mathrm{R}$ Development Core Team 2013).

To assess the variability explained by the fixed and random effects, we calculated the pseudo- $R^{2}$. We did not perform this 
analysis on the abundance model, as currently it is not possible to calculate the pseudo- $R^{2}$ of a GLMM with a negative binomial distribution (Nakagawa \& Schielzeth 2013; Johnson 2014). To calculate the pseudo- $R^{2}$ for the species richness model, we built a mixed model including all parameters that were included in models with a $\triangle \mathrm{AICc}$ below two. Then, we calculated the marginal and conditional pseudo- $R^{2}$ using the function 'r.squaredGLMM' implemented in the 'MuMIN' package (Barton 2013). The marginal pseudo- $R^{2}$ describes the proportion of variance explained by the fixed factors alone, while the conditional pseudo- $R^{2}$ describes the proportion of variance explained by both the fixed and random factors (Nakagawa \& Schielzeth 2013).

\section{Results}

A total of 12954 individuals were collected belonging to 50 species (for species list see Table S1, Supporting information): 8041 individuals belonging to 40 species were collected in organic farms, while 4913 individuals belonging to 35 species were collected in conventional farms. Fifteen species were only found on organic farms, while 10 were only found on conventional farms. Two species were dominant accounting for more than $80 \%$ of the total abundance. Siphona geniculata (DeGeer) and Eriothrix rufomaculata (DeGeer) represented $68 \%$ and $19 \%$ of the individuals collected, respectively. Siphona geniculata is one of the few parasitoids known to attack crane fly larvae (Diptera: Tipulidae) which are important agricultural pests damaging grasslands and cereals, although they can also be a problem in other crops, particularly where they are grown after grass leys (Belshaw 1993; Blackshaw \& Coll 1999). Eriothrix rufomaculata is a parasitoid of lepidopteran larvae, known to attack pyralid larvae (Lepidoptera: Pyralidae) in grasses (Paston \& Rotheray 2009).

For tachinid abundance, six plausible models were selected $(\triangle \mathrm{AICc}<2$, Table $\mathrm{S} 2)$. The sum of model weights for each predictor gave support for strong effects of region, landscape, farm management, habitat and trap location on tachinid abundance (Table 1). This indicates that the tachinid abundance was higher in Central South West $($ mean $=48.56 \pm 5.72 \mathrm{SE}$ ) than in North Midlands $(21.38 \pm 2.72 \mathrm{SE})$, higher in hotspots $(42.63 \pm 5.44 \mathrm{SE})$ than in coldspots $(27.18 \pm 3.43 \mathrm{SE}$ ) (Fig. 2b), higher in organic $(43.47 \pm 5.86 \mathrm{SE})$ than in conventional $(26.27 \pm 2.61 \mathrm{SE}$ ) farms (Fig. 2a), higher in grasslands $(42.09 \pm 5.54 \mathrm{SE})$ than in arable crops $(27.86 \pm 3.35 \mathrm{SE})$ and higher in the field margins $(48.26 \pm 5.60 \mathrm{SE})$ than in the field centres $(21.24 \pm 2.84 \mathrm{SE})$. We also found a good support for two interactions: management $\times$ habitat and landscape $\times$ habitat. The first interaction (management $\times$ habitat) indicated that organic management exhibited higher abundance than conventional management in arable fields but not in grassland fields (Fig. 3a). Similarly, hotspots had a higher abundance than coldspots in arable fields but not in grasslands (Fig. 3b; landscape $\times$ habitat interaction). Although less strong, we found two additional interactions: landscape $\times$ location and landscape $\times$ management. The first interaction (landscape $\times$ location) indicated that the difference in abundance between field margins and centres was less evident in hotspots than in coldspots. The second interaction (landscape $\times$ management) indicated that in hotspots, the abundance of tachinids on conventional farms was more similar to that of organic farms.

For tachinid species richness, 10 plausible models were selected $(\triangle \mathrm{AICc}<2$, Table $\mathrm{S} 2)$. Similar to tachinid abundance, we found a strong effect of region, landscape, farm management, habitat and trap location on tachinid species richness (Table 1). This indicates that the tachinid species richness was higher in Central South (3.28 $\pm 0 \cdot 12 \mathrm{SE})$ than in North Midlands $(2 \cdot 18 \pm 0 \cdot 11 \mathrm{SE})$, higher in hotspots $(3.02 \pm 0.13 \mathrm{SE})$ than in coldspots $(2.43 \pm 0 \cdot 11 \mathrm{SE})$ (Fig. 2d), higher in organic (2.92 $\pm 0.13 \mathrm{SE})$ than in conventional (2.52 $\pm 0.11 \mathrm{SE}$ ) farms (Fig. 2c), higher in arable crops $(2 \cdot 80 \pm 0 \cdot 13 \mathrm{SE})$ than in grasslands
Table 1. Sum of Akaike weights $\left(\Sigma w_{\mathrm{i}}\right)$ across all models for tachinid abundance and species richness. For each predictor, $\Sigma w_{\mathrm{i}}$ is the sum of weights of the models that contain that variable. $\Sigma w_{\mathrm{i}}$ can vary between 0 and 1 and represents the relative importance of the variables (Burnham \& Anderson 2002)

\begin{tabular}{lll}
\hline & $\begin{array}{l}\text { Abundance } \\
\Sigma w_{\mathrm{i}}\end{array}$ & $\begin{array}{l}\text { Species richness } \\
\Sigma w_{\mathrm{i}}\end{array}$ \\
\hline Habitat & $1 \cdot 00$ & $0 \cdot 96$ \\
Landscape & $1 \cdot 00$ & $1 \cdot 00$ \\
Location & $1 \cdot 00$ & $1 \cdot 00$ \\
Management & $1 \cdot 00$ & $0 \cdot 96$ \\
Region & $1 \cdot 00$ & $1 \cdot 00$ \\
Habitat $\times$ Landscape & $0 \cdot 99$ & $0 \cdot 85$ \\
Habitat $\times$ Location & $0 \cdot 44$ & $0 \cdot 69$ \\
Habitat $\times$ Management & $1 \cdot 00$ & $0 \cdot 47$ \\
Landscape $\times$ Location & 0.64 & $0 \cdot 72$ \\
Landscape $\times$ Management & $0 \cdot 50$ & $0 \cdot 31$ \\
Location $\times$ Management & $0 \cdot 42$ & $0 \cdot 41$ \\
Habitat $\times$ Landscape $\times$ Location & $0 \cdot 12$ & $0 \cdot 19$ \\
Habitat $\times$ Landscape $\times$ Management & $0 \cdot 26$ & $0 \cdot 05$ \\
Habitat $\times$ Location $\times$ Management & $0 \cdot 14$ & $0 \cdot 08$ \\
Landscape $\times$ Location $\times$ Management & $0 \cdot 07$ & $0 \cdot 03$ \\
Habitat $\times$ Landscape $\times$ Location $\times$ Management & 0 & 0 \\
\hline
\end{tabular}



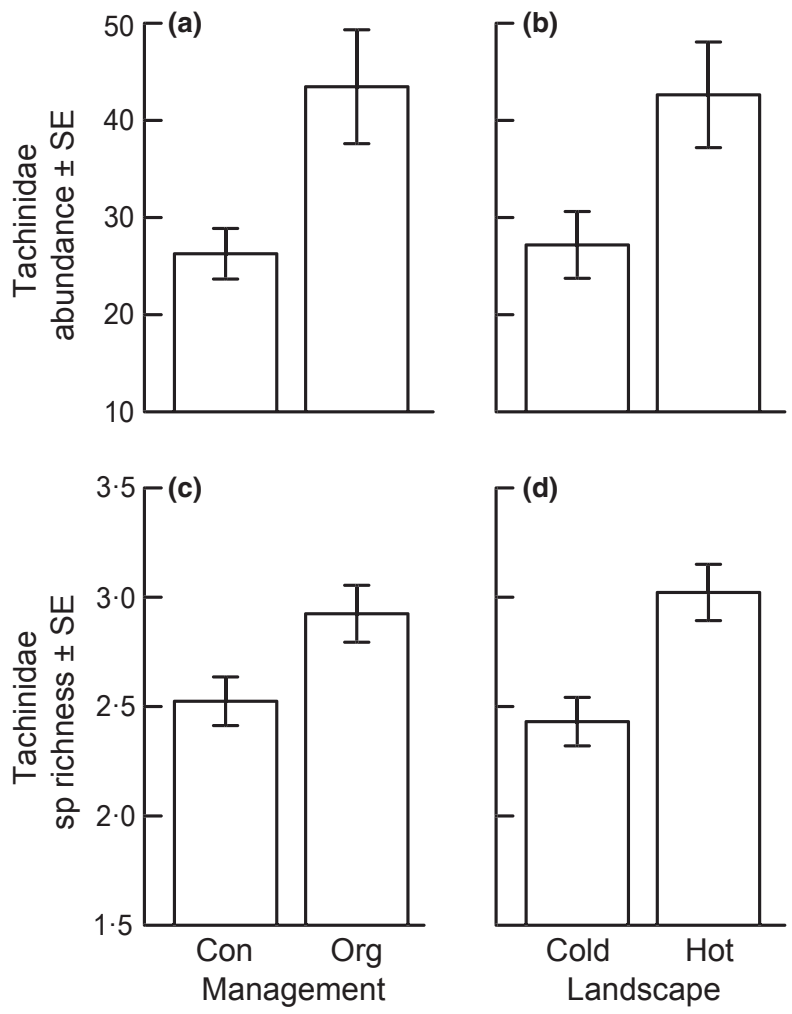

Fig. 2. Mean values $( \pm \mathrm{SE})$ of tachinid abundance $(\mathrm{a}, \mathrm{b})$ and species richness (c, d) per farm management (Con: conventional, Org: organic) and landscape composition (Cold: coldspot, Hot: hotspot).
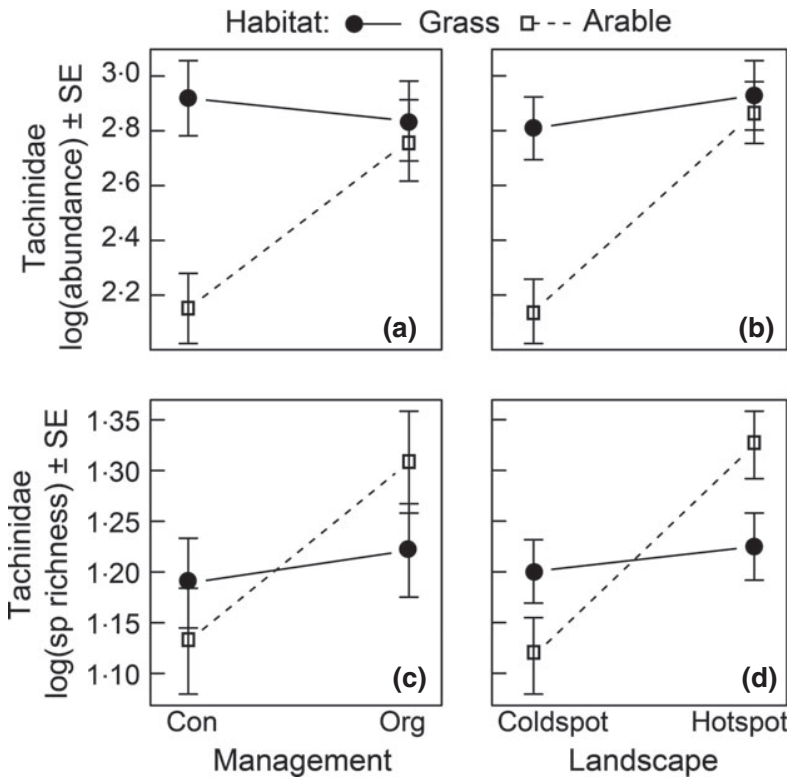

Fig. 3. Interaction between management (Con: conventional, Org: organic) and habitat (a, c) and between landscape and habitat $(b, d)$ on tachinid log-abundance and log-species richness. Dots represent mean values, and bars represent the SE.

$(2.64 \pm 0.12 \mathrm{SE})$ and higher in the field margins $(3.36 \pm 0.13 \mathrm{SE})$ than in the field centres $(2.08 \pm 0.10$ $\mathrm{SE})$. As above, we also found strong support for an interaction between landscape and habitat, where hotspots displayed higher species richness than coldspots in arable fields, but not in grasslands (Fig. 3d). Although less supported, we found two additional interactions: habitat $\times$ location and landscape $\times$ location. These interactions indicate that the differences in species richness between field margins and centres were less evident in grasslands than in arable crops and in hotspots than in coldspots. We further found that fixed effects explained the majority of the variability of the mixed model containing all the parameters with a $\triangle \mathrm{AICc}<2$. Specifically, we found a pseudo- $R^{2}$ of 0.30 for the proportion of variance explained by the fixed factors alone, while for the proportion of variance explained by both the fixed and random factors, we found a pseudo- $R^{2}$ of 0.32 .

\section{Discussion}

Our study indicates a positive effect of organic farming on tachinid parasitoid diversity at multiple spatial scales. We found higher abundance and species richness both on organic farms and in hotspot landscapes. However, the tachinid parasitoid response was complex, and various interactions between the organic farming and local habitat were found. In particular, the positive effect of organic management was clear for arable fields, while it was almost neutral for grasslands, both at the local and at the landscape scale. These results have important implications for management, as any attempt to enhance parasitoid diversity in agricultural landscapes needs to consider the local management in relation to habitat type, location within the field and agricultural management in the landscape.

At the local scale, we found that tachinid diversity was always higher in the field margins. Several studies have shown that field margins are important semi-natural habitats within agricultural landscapes hosting high insect diversity (Marshall \& Moonen 2002; Benton, Vickery \& Wilson 2003; Carvell et al. 2007; Olson \& Wäckers 2007; Vickery, Feber \& Fuller 2009; Macfadyen \& Muller 2013; Ó hUallacháin et al. 2014; Dainese et al. 2015), but how margins interact with their adjacent fields is less clear. For example, Olson \& Wäckers (2007) showed that managing margins for beneficial insects along conventional fields of cotton increased the diversity of tachinid parasitoids, but there was no effect on the spillover of individuals into the field. By contrast, Schröter \& Irmler (2013) found in a transitional experiment from conventional to organic farming that after 4 years under organic farming the community of carabid predators of the field centre resembled that of the field margins. In our study, we found no effects of local management on the spillover of tachinids. However, we found a marginal effect of the landscape on the local spillover of parasitoids from the margin to the field centre, suggesting that for highly mobile organisms, the effect of management needs to be considered at larger scales. 
At the local and landscape scales, we further found that tachinid diversity was differently affected by the organic farming depending on habitat type (grassland or arable land). Specifically, the positive effect of organic management was exhibited strongly in arable fields, but was almost absent for grasslands. Similar results have been found by other authors (Eyre \& Leifert 2011; Kleijn et al. 2011; Batáry et al. 2012; Eyre, Luff \& Leifert 2013; Scheper et al. 2013), suggesting that differences in the effectiveness of organic farming between these habitats may be explained by differences in disturbance together with their specific management. As arable crops are generally more disturbed by agricultural activities than grasslands, the benefit generated by organic management is expected to be more evident in the former (Kleijn et al. 2011; Scheper et al. 2013). On the one hand, in arable crops under conventional agriculture, insects are expected to be negatively affected by the use of chemical pesticides, compared to organic farms where such chemicals are not applied (Longley 1999; Holland, Winder \& Perry 2000; Boatman et al. 2007; Geiger et al. 2010). On the other hand, pesticides are not usually applied in grasslands in both organic and conventional farms, and often the intensity of management does not differ significantly between the two farming systems (Geiger et al. 2010; Batáry et al. 2012; Gaujour et al. 2012). In both conventional and organic grasslands, insect diversity is mainly affected by fertilization and mechanical disturbances such as mowing frequency and grazing intensity (van Elsen 2000; Kruess \& Tscharntke 2002; Humbert, Ghazoul \& Walter 2009; Marini et al. 2009; Gaujour et al. 2012). The main difference between organic and conventional grasslands is in their use of organic and mineral fertilizers, respectively, which are actually thought to have very similar effects on flower-visiting insects such as tachinids (Al-Dobai, Reitz \& Sivinski 2012). Finally, we found that organic arable land yielded even slightly higher species richness than organic grasslands. This is probably related to the higher presence of flowering weeds in the organic cereal fields that can provide alternative resources to tachinids. In contrast, organic grasslands were provably intensively managed (both fertilization and grazing) reducing flowering plant diversity (Gabriel et al. 2010).

Although the local factors explained above were important determinants of the diversity of tachinids, we also found that the proportion of organic land in the landscape played a major role. A greater cover of land under organic farming in the landscape enhanced the diversity of tachinids that can colonize both organic and conventional farms. Specifically, we found that the abundance and species richness of tachinid parasitoids was always higher within hotspot landscapes. The proportion of organic land in the landscape has been found to be important for other insect groups such as butterflies, epigeal arthropods and solitary bees (Gabriel et al. 2010). These effects may arise because the distribution and persistence of species across landscapes depend on the species' dispersal ability and the proximity of suitable habitats that can support viable population sources (Pulliam 1988; Hanski \& Ovaskainen 2002). As tachinid flies have been found to respond to habitat connectivity (Letourneau, Bothwell Allen \& Stireman 2012; Inclán, Cerretti \& Marini 2014), the amount of organic farming in agricultural landscapes appears to be a potential means of re-establishing heterogeneity of farmland habitats, thereby enhancing farmland parasitoid diversity (Benton, Vickery \& Wilson 2003). Therefore, to restore biodiversity in agricultural landscapes, strategies promoting organic agriculture should aim to increase both the total extent of organic farming and the contiguity of individual organic farms.

\section{SYNTHESIS AND APPLICATIONS}

Our results have important implications for parasitoid conservation in agricultural landscapes. In particular, any attempt to enhance parasitoid diversity, by means of organic management, needs to consider the local management in relation to habitat type and agricultural management in the landscape. At the local scale, organic management in arable fields is clearly enhancing tachinid diversity, while the organic management of grasslands did not provide any benefit. As it has been shown by other authors, the effects of AES measures increase with the size of the ecological contrast created by the measure (Kleijn et al. 2011; Scheper et al. 2013). The contrast between conventional and organic cereal fields is much higher than that between conventional and organic grasslands. At the landscape scale, our results exemplify how landscapes with a higher proportion of organic land improved the overall diversity of tachinid parasitoids. Conventional farms had $42 \%$ and $18 \%$ higher tachinid abundance and species richness, respectively, in organic landscapes than in landscapes with a high cover of conventional agriculture. As tachinid parasitoids have a wide range of hosts, increasing their diversity may also increase the potential to control a larger spectrum of pests. Thus, as the benefits of organic management to biodiversity spread beyond the borders of individual farms, any assessment of organic farming should incorporate these positive externalities. To restore parasitoid diversity in agricultural landscapes, the promotion of organic agriculture (i.e. as an AES strategy) should aim to increase both the total extent of organic farming and the connectivity of individual organic farms. However, future research is still needed to demonstrate the specific contribution of parasitoids to key ecosystem services such as biological control.

\section{Acknowledgements}

We thank the farmers, the field and laboratory assistants and the RELU SCALE team for collaboration. The research was funded as part of the UK Research Councils' Rural Economy and Land Use Programme 
(RELU) (RES-227-25-0006). DJI was supported by a PhD Fellowship from the CARIPARO Foundation. LM was supported by the European Community's Seventh Framework Programme under grant agreement no. 311781, LIBERATION Project (www.fp7liberation.eu).

\section{Data accessibility}

Tachinid abundance and species richness in organic and conventional farms: data available from the Dryad Digital Repository http://dx.doi.org/ 10.5061/dryad.7p1d3 (Inclán et al. 2015). List of the tachinid species found in the study sites: uploaded as Supporting Information.

\section{References}

Al-Dobai, S., Reitz, S. \& Sivinski, J. (2012) Tachinidae (Diptera) associated with flowering plants: estimating floral attractiveness. Biological Control, 61, 230-239

Batáry, P.. Holzschuh, A., Orci, K.M., Samu, F. \& Tscharntke, T. (2012) Responses of plant, insect and spider biodiversity to local and landscape scale management intensity in cereal crops and grasslands. Agriculture, Ecosystems \& Environment, 146, 130-136.

Batchelor, T.P., Hardy, I.C., Barrera, J.F. \& Pérez-Lachaud, G. (2005) Insect gladiators II: competitive interactions within and between bethylid parasitoid species of the coffee berry borer, Hypothenemus hampei (Coleoptera: Scolytidae). Biological Control, 33, 194-202.

Barton, K. (2013) MuMIn: Multi-model inference. R package version 1.9.13. Available at: http://CRAN.R-project.org/package $=$ MuMIn (accessed 27 September 2014).

Belshaw, R. (1993) Tachinid Flies. Diptera: Tachinidae. Handbooks for the Identification of British Insects 10, Part 4a(i). Royal Entomological Society of London, London, UK

Bengtsson, J., Ahnström, J. \& Weibull, A.C. (2005) The effects of organic agriculture on biodiversity and abundance: a meta-analysis. Journal of Applied Ecology, 42, 261-269.

Benton, T.G., Vickery, J.A. \& Wilson, J.D. (2003) Farmland biodiversity: is habitat heterogeneity the key? Trends in Ecology \& Evolution, 18, 182-188.

Bianchi, F.J.J.A., Booij, C.J.H. \& Tscharntke, T. (2006) Sustainable pest regulation in agricultural landscapes: a review on landscape composition, biodiversity and natural pest control. Proceedings of the Royal Society B, 273, 1715-1727.

Blackshaw, R.P. \& Coll, C. (1999) Economically important leatherjackets of grassland and cereals: biology, impact and control. Integrated Pest Management Reviews, 4, 145-162.

Boatman, N.D., Parry, H.R., Bishop, J.D. \& Cuthbertson, A.G. (2007) Impacts of agricultural change on farmland biodiversity in the UK. Biodiversity Under Threat (eds R.E. Hester \& R.M. Harrison), pp. 1-32. RSC Publishing, Cambridge, UK.

Bolker, B.M., Brooks, M.E., Clark, C.J., Geange, S.W., Poulsen, J.R., Stevens, M.H.H. \& White, J.S. (2008) Generalized linear mixed models: a practical guide for ecology and evolution. Trends in Ecology and Evolution, 24, 127-135.

Burnham, K.P. \& Anderson, D.R. (2002) Model Selection and Multimodel Inference: A Practical Information-Theoretic Approach, 2nd edn. Springer, New York, New York, USA.

Carvell, C., Meek, W.R., Pywell, R.F., Goulson, D. \& Nowakowski, M. (2007) Comparing the efficacy of agri-environment schemes to enhance bumble bee abundance and diversity on arable field margins. Journal of Applied Ecology, 44, 29-40.

Cerretti, P. (2010) I tachinidi della fauna italiana (Diptera Tachinidae), con chiave interattiva dei generi ovest paleartici, Vol. I \& II + CD-rom. Cierre Edizioni, Verona, Italy.

Cerretti, P., O’Hara, J.E., Wood, D.M., Shima, H., Inclán, D.J. \& Stireman, J.O.I.I.I. (2014) Signal through the noise? Phylogeny of the Tachinidae (Diptera) as inferred from morphological evidence. System atic Entomology, 39, 335-353.

Cerretti, P., Tschorsnig, H.-P., Lopresti, M. \& Di Giovanni, F. (2012) MOSCHweb - a matrix-based interactive key to the genera of the Palaearctic Tachinidae (Insecta, Diptera). ZooKeys, 205, 5-18.

Clough, Y., Holzschuh, A., Gabriel, D., Purtauf, T., Kleijn, D., Kruess, A., Steffan-Dewenter, I., Kleijn, D. \& Tscharntke, T. (2007) Alpha and beta diversity of arthropods and plants in organically and conventionally managed wheat fields. Journal of Applied Ecology, 44, 804-812.
Crowder, D.W., Northfield, T.D., Strand, M.R. \& Snyder, W.E. (2010) Organic agriculture promotes evenness and natural pest control. Nature, 466, 109-112.

Dainese, M., Inclán, D.J., Sitzia, T. \& Marini, L. (2015) Testing scaledependent effects of semi-natural habitats on farmland biodiversity. Ecological Applications, doi: 10.1890/14-1321.1.

van Elsen, T. (2000) Species diversity as a task for organic agriculture in Europe. Agriculture, Ecosystems \& Environment, 77, 101-109.

Eyre, M.D. \& Leifert, C. (2011) Crop and field boundary influences on the activity of a wide range of beneficial invertebrate groups on a split conventional/organic farm in northern England. Bulletin of Entomological Research, 101, 135-144.

Eyre, M.D., Luff, M.L. \& Leifert, C. (2013) Crop, field boundary, productivity and disturbance influences on ground beetles (Coleoptera, Carabidae) in the agroecosystem. Agriculture, Ecosystems \& Environment, 165, $60-67$.

Finke, D.L. \& Denno, R.F. (2004) Predator diversity dampens trophic cascades. Nature, 429, 407-410.

Fournier, D.A., Skaug, H.J., Ancheta, J., Ianelli, J., Magnusson, A., Maunder, M., Nielsen, A. \& Sibert, J. (2012) AD Model Builder: using automatic differentiation for statistical inference of highly parameterized complex nonlinear models. Optimization Methods and Software, 27, 233-249.

Fuller, R.J., Norton, L.R., Feber, R.E., Johnson, P.J., Chamberlain, D.E., Joys, A.C. et al. (2005) Benefits of organic farming to biodiversity vary among taxa. Biology Letters, 1, 431-434.

Gabriel, D., Roschewitz, I., Tscharntke, T. \& Thies, C. (2006) Beta diversity at different spatial scales: plant communities in organic and conventional agriculture. Ecological Applications, 16, 2011-2021.

Gabriel, D., Carver, S.J., Durham, H., Kunin, W.E., Palmer, R.C., Sait, S.M., Stagl, S. \& Benton, T.G. (2009) The spatial aggregation of organic farming in England and its underlying environmental correlates. Journal of Applied Ecology, 46, 323-333.

Gabriel, D., Sait, S.M., Hodgson, J.A., Schmutz, U., Kunin, W.E. \& Benton, T.G. (2010) Scale matters: the impact of organic farming on biodiversity at different spatial scales. Ecology Letters, 13, 858-869.

Gaujour, E., Amiaud, B., Mignolet, C. \& Plantureux, S. (2012) Factors and processes affecting plant biodiversity in permanent grasslands. A review. Agronomy for Sustainable Development, 32, 133-160.

Geiger, F., Bengtsson, J., Berendse, F., Weisser, W.W., Emmerson, M., Morales, M.B. et al. (2010) Persistent negative effects of pesticides on biodiversity and biological control potential on European farmland. Basic and Applied Ecology, 11, 97-105.

Grenier, S. (1988) Applied biological control with tachinid flies (Diptera, Tachinidae): a review. Anzeiger für Schädlingskunde, Pflanzenschutz, Umweltschutz, 61, 49-56.

Hanski, I. \& Ovaskainen, O. (2002) Extinction debt at extinction threshold. Conservation Biology, 16, 666-673.

Holland, J.M., Winder, L. \& Perry, J.N. (2000) The impact of dimethoate on the spatial distribution of beneficial arthropods in winter wheat. Annals of Applied Biology, 136, 93-105.

Holzschuh, A., Steffan-Dewenter, I. \& Tscharntke, T. (2008) Agricultural landscapes with organic crops support higher pollinator diversity. Oikos, 117, 354-361.

Holzschuh, A., Steffan-Dewenter, I. \& Tscharntke, T. (2010) How do landscape composition and configuration, organic farming and fallow strips affect the diversity of bees, wasps and their parasitoids? Journal of Animal Ecology, 79, 491-500.

Humbert, J.Y., Ghazoul, J. \& Walter, T. (2009) Meadow harvesting techniques and their impacts on field fauna. Agriculture, Ecosystems \& Environment, 130, 1-8.

Inclán, D.J., Cerretti, P., Gabriel, D., Benton, T.G., Sait, S.M., Kunin, W.E., Gillespie, M.A.K. \& Marini, L. (2015) Data from: organic farming enhances parasitoid diversity at the local and landscape scale. Dryad Digital Repository, http://dx.doi.org/10.5061/dryad.7p1d3

Inclán, D.J., Cerretti, P. \& Marini, L. (2014) Interactive effects of area and connectivity on the diversity of tachinid parasitoids in highly fragmented landscapes. Landscape Ecology, 29, 879-889.

Johnson, P.C.D. (2014) Extension of Nakagawa \& Schielzeth's R ${ }_{\text {GLMM }}$ to random slopes models. Methods in Ecology and Evolution, 5, 944946

Jonsson, M., Buckley, H.L., Case, B.S., Wratten, S.D., Hale, R.J. \& Didham, R.K. (2012) Agricultural intensification drives landscape-context effects on host-parasitoid interactions in agroecosystems. Journal of Applied Ecology, 49, 706-714. 
Kruess, A. \& Tscharntke, T. (2002) Contrasting responses of plant and insect diversity to variation in grazing intensity. Biological Conservation, 106, 293-302.

Kleijn, D., Rundlof, M., Scheper, J., Smith, H.G. \& Tscharntke, T. (2011) Does conservation on farmland contribute to halt biodiversity decline? Trends in Ecology \& Evolution, 26, 474-481.

Letourneau, D.K. \& Bothwell, S.G. (2008) Comparison of organic and conventional farms: challenging ecologists to make biodiversity functional. Frontiers in Ecology and the Environment, 6, 430-438.

Letourneau, D.K., Bothwell Allen, S.G. \& Stireman, J.O. (2012) Perennial habitat fragments, parasitoid diversity and parasitism in ephemeral crops. Journal of Applied Ecology, 49, 1405-1416.

Lohaus, K., Vidal, S. \& Thies, C. (2013) Farming practices change food web structures in cereal aphid-parasitoid-hyperparasitoid communities. Oecologia, 171, 249-259.

Longley, M. (1999) A review of pesticide effects upon immature aphid parasitoids within mummified hosts. International Journal of Pest Management, 45, 139-145.

Macfadyen, S., Craze, P.G., Polaszek, A., van Achterberg, K. \& Memmott, J. (2011) Parasitoid diversity reduces the variability in pest control services across time on farms. Proceedings of the Royal Society B: Biological Sciences, 278, 3387-3394.

Macfadyen, S., Gibson, R., Polaszek, A., Morris, R.J., Craze, P.G., Planqué, R., Symondson, W.O.C. \& Memmott, J. (2009) Do differences in food web structure between organic and conventional farms affect the ecosystem service of pest control? Ecology Letters, 12, 229-238.

Macfadyen, S. \& Muller, W. (2013) Edges in agricultural landscapes: species interactions and movement of natural enemies. PLoS ONE, 8, e59659.

Marini, L., Fontana, P., Klimek, S., Battisti, A. \& Gaston, K.J. (2009) Impact of farm size and topography on plant and insect diversity of managed grasslands in the Alps. Biological Conservation, 142, 394- 403.

Marshall, E.J.P. \& Moonen, A.C. (2002) Field margins in northern Europe: their functions and interactions with agriculture. Agriculture, Ecosystems \& Environment, 89, 5-21.

Nakagawa, S. \& Schielzeth, H. (2013) A general and simple method for obtaining $\mathrm{R}^{2}$ from generalized linear mixed-effects models. Methods in Ecology and Evolution, 4, 133-142.

O'Hara, J.E. (2013) History of tachinid classification (Diptera, Tachinidae). ZooKeys, 316, 1-34.

Ó hUallacháin, D., Anderson, A., Fritch, R., McCormack, S., Sheridan, H. \& Finn, J.A. (2014) Field margins: a comparison of establishment methods and effects on hymenopteran parasitoid communities. Insect Conservation and Diversity, 7, 289-307.

Olson, D.M. \& Wäckers, F.L. (2007) Management of field margins to maximize multiple ecological services. Journal of Applied Ecology, 44, $13-21$

Paston, S. \& Rotheray, G.E. (2009) Eriothrix rufomaculata (De Geer, 1776) (Diptera, Tachinidae) reared from Chrysoteuchia culmella (Linnaeus) (Lepidoptera, Pyralidae) - a first British host record. Dipterists Digest, 16, 3-6.

Pérez-Lachaud, G., Batchelor, T.P. \& Hardy, I.C. (2004) Wasp eat wasp: facultative hyperparasitism and intra-guild predation by bethylid wasps. Biological Control, 30, 149-155.

Pulliam, H.R. (1988) Sources, sinks, and population regulation. American Naturalist, 132, 652-661.
R Development Core Team (2013) The R foundation for Statistical Computing, ver 3.0.2. Vienna University of Technology, Vienna, Austria. Available at: http://www.r-project.org/

Rundlöf, M., Edlund, M. \& Smith, H.G. (2010) Organic farming at local and landscape scales benefits plant diversity. Ecography, 33, 514-522.

Scheper, J., Holzschuh, A., Kuussaari, M., Potts, S.G., Rundlöf, M., Smith, H.G. \& Kleijn, D. (2013) Environmental factors driving the effectiveness of European agri-environmental measures in mitigating pollinator loss-a meta-analysis. Ecology Letters, 16, 912-920.

Schröter, L. \& Irmler, U. (2013) Organic cultivation reduces barrier effect of arable fields on species diversity. Agriculture, Ecosystems \& Environment, 164, 176-180.

Stireman, J.O. III, O'Hara, J.E. \& Wood, D.M. (2006) Tachinidae: evolution, behavior, and ecology. Annual Review of Entomology, 51, 525-555. Swift, M.J., Vandermeer, J., Ramakrishnan, P.S., Anderson, J.M., Ong, C.K. \& Hawkins, B.A. (1996) Biodiversity and agroecosystem function. Functional Roles of Biodiversity: A Global Perspective (eds J.H. Cushman, H.A. Mooney, E. Medina, O.E. Sala \& E.D. Schulze), pp. 261298. Wiley, Chichester, UK

Thies, C., Haenke, S., Scherber, C., Bengtsson, J., Bommarco, R., Clement, L.W. et al. (2011) The relationship between agricultural intensification and biological control: experimental tests across Europe. Ecological Applications, 21, 2187-2196.

Tilman, D., Fargione, J., Wolff, B., D’Antonio, C., Dobson, A., Howarth, R. et al. (2001) Forecasting agriculturally driven global environmental change. Science, 292, 281-284.

Tuck, S.L., Winqvist, C., Mota, F., Ahnström, J., Turnbull, L.A. \& Bengtsson, J. (2014) Land-use intensity and the effects of organic farming on biodiversity: a hierarchical meta-analysis. Journal of Applied Ecology, 51, 746-755.

Vickery, J.A., Feber, R.E. \& Fuller, R.J. (2009) Arable field margins managed for biodiversity conservation: a review of food resource provision for farmland birds. Agriculture, Ecosystems \& Environment, 133, 1-13.

Whittingham, M.J., Stephens, P.A., Bradbury, R.B. \& Freckleton, R.P (2006) Why do we still use stepwise modelling in ecology and behaviour? Journal of Animal Ecology, 75, 1182-1189.

Wilby, A. \& Thomas, M.B. (2002) Natural enemy diversity and pest control: patterns of pest emergence with agricultural intensification. Ecology Letters, 5, 353-360.

Received 10 November 2014; accepted 28 April 2015

Handling Editor: David Kleijn

\section{Supporting Information}

Additional Supporting Information may be found in the online version of this article.

Table S1. List of the tachinid species found in the study sites.

Table S2. Plausible candidate models (within $2 \Delta \mathrm{AIC}$ of the top model) explaining species richness and abundance of tachinid parasitoids. 